\title{
LATE HOLOCENE CLIMATE VARIABILITY FROM ST. CROIX, USVI REEF CORALS
}

Dakota Keene $^{1}$, Amy Wagner ${ }^{1}$, Chad Lane ${ }^{2}$

SACRAMENTO STATE

${ }^{1}$ Department of Geology, California State University, Sacramento, CA 95819
${ }^{2}$ Department of Earth and Ocean Sciences, University of North Carolina, Wilmington, NC 28403

\section{Abstract}

We present a multi-century climate record using the skeletal geochemistry of Siderastrea siderea and Orbicella faveolata corals collected near Salt River Bay, St. Croix, USVI. Samples ranging in age from modern to approximately 2100 years old were collected, slabbed, and milled with each coral representing approximately 25 to 40 years of growth. Skeletal $\delta^{18} \mathrm{O}$ values correlate strongly with sea surface temperature (SST) and sea surface salinity (SSS). Seasona variations in skeletal $\delta$ O values are controlled primarily by changes in SST and Andusily by infered changes in water $\delta$ lix due to precipitation and runoff Analysis of these variations in the St. Croix corals indicates that SST and SSS 政 masking the $\delta$ O signal. Samples were also analyzed with Laser Ablation (5)

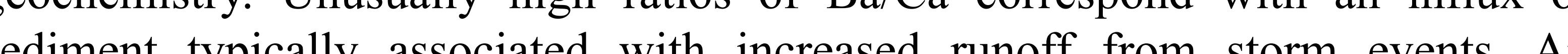
crese in averal $\mathrm{B} / \mathrm{Ca}$ values when $\delta^{18} \mathrm{O}$ values are static is likely a

\section{Methods}

Study Area: Samples were collected and cored near the mouth of Salt River Bay on the island of St. Croix, USVI (Figures 1 and 2).

Preparation: Each core was slabbed and sonicated before being $\mathrm{x}$-rayed, $\mathrm{U}$

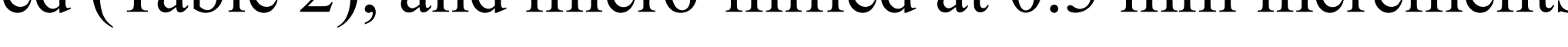

Stable Isotope Daca: Millod coral naterial was analyzed on a Thermo Gasbench I/H inMS) a the Carolina, Wilmington (UNCW CMS).

is ICP-MS to obtain Barium to Calcium ratios in the Stable Isotope Laboratory at the UC-Davis Earth and Planetary Sciences Department.

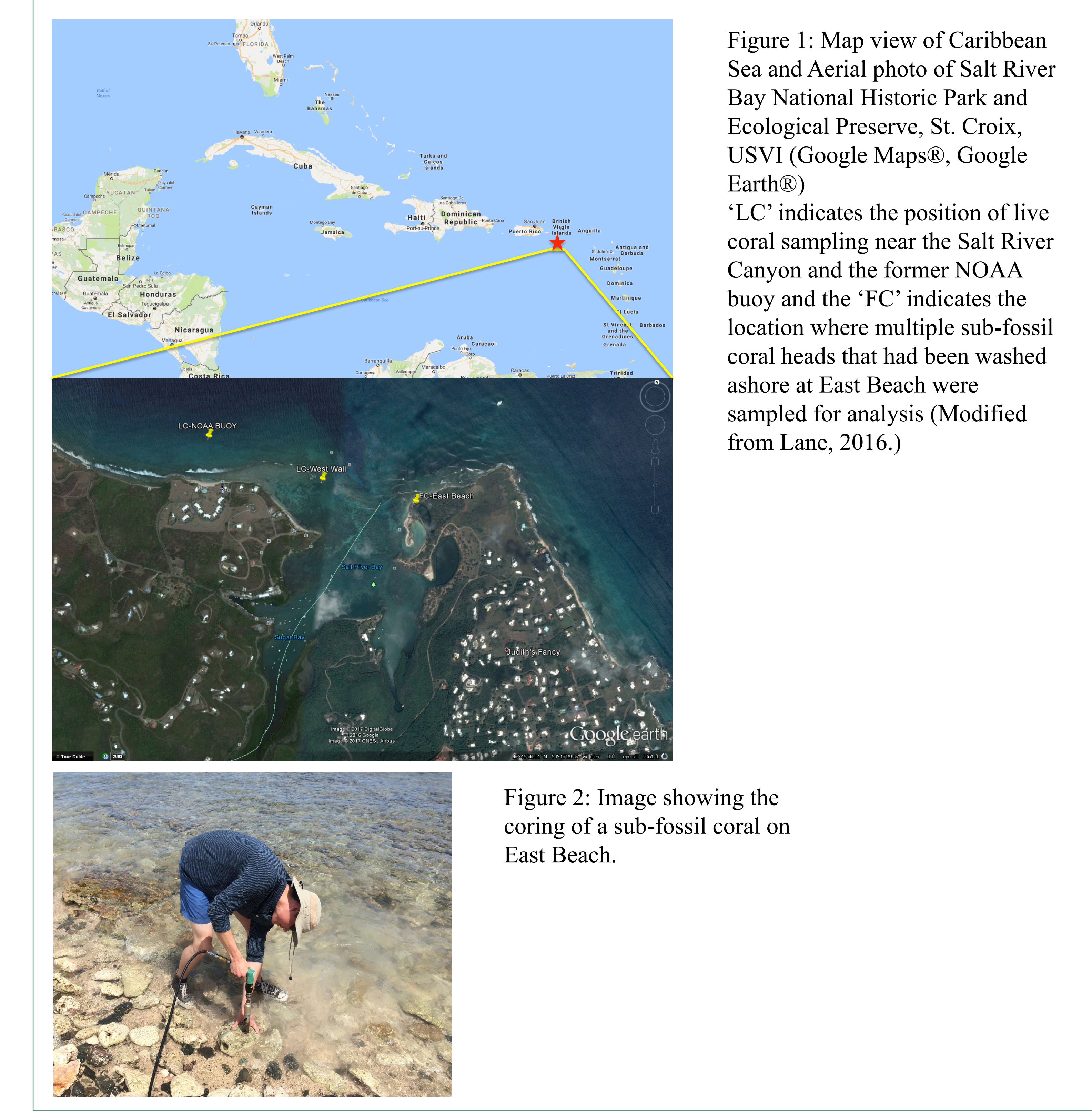

\section{Results}

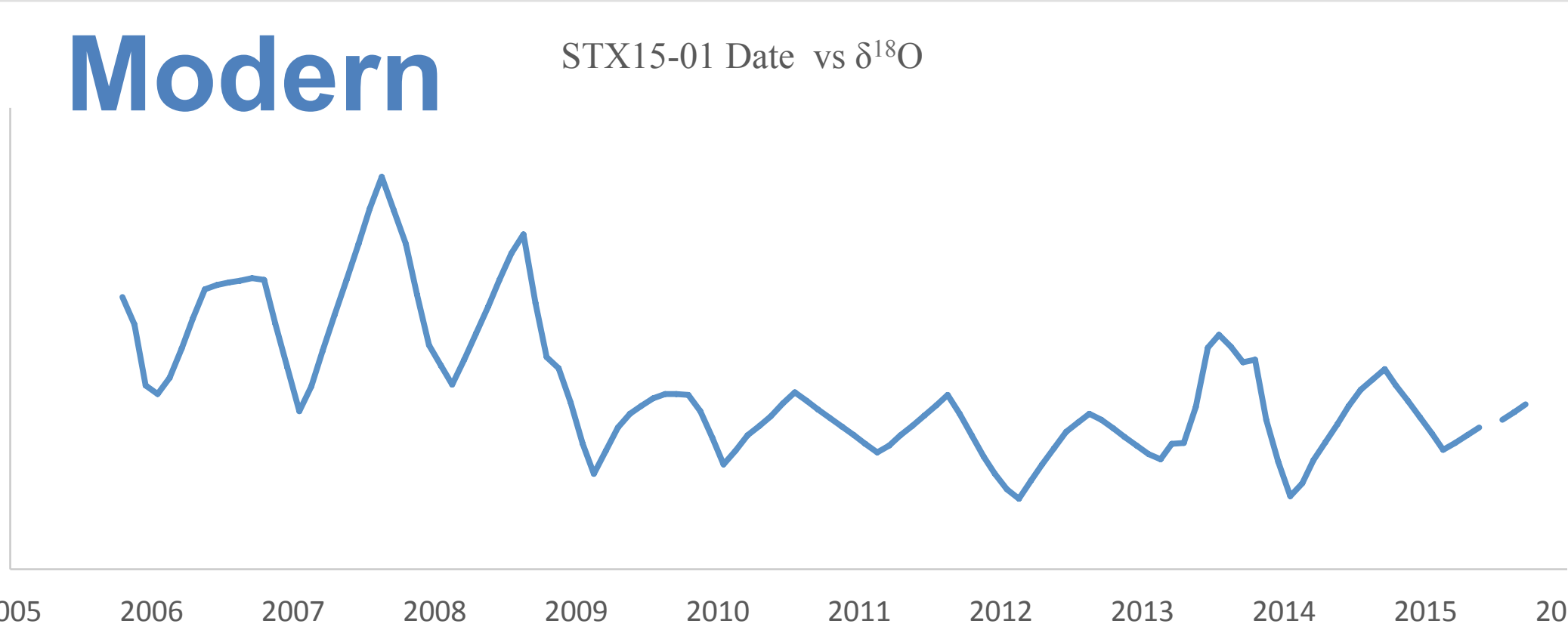

Figure 3: Stable oxygen
from 2005 to 2015 C.E.

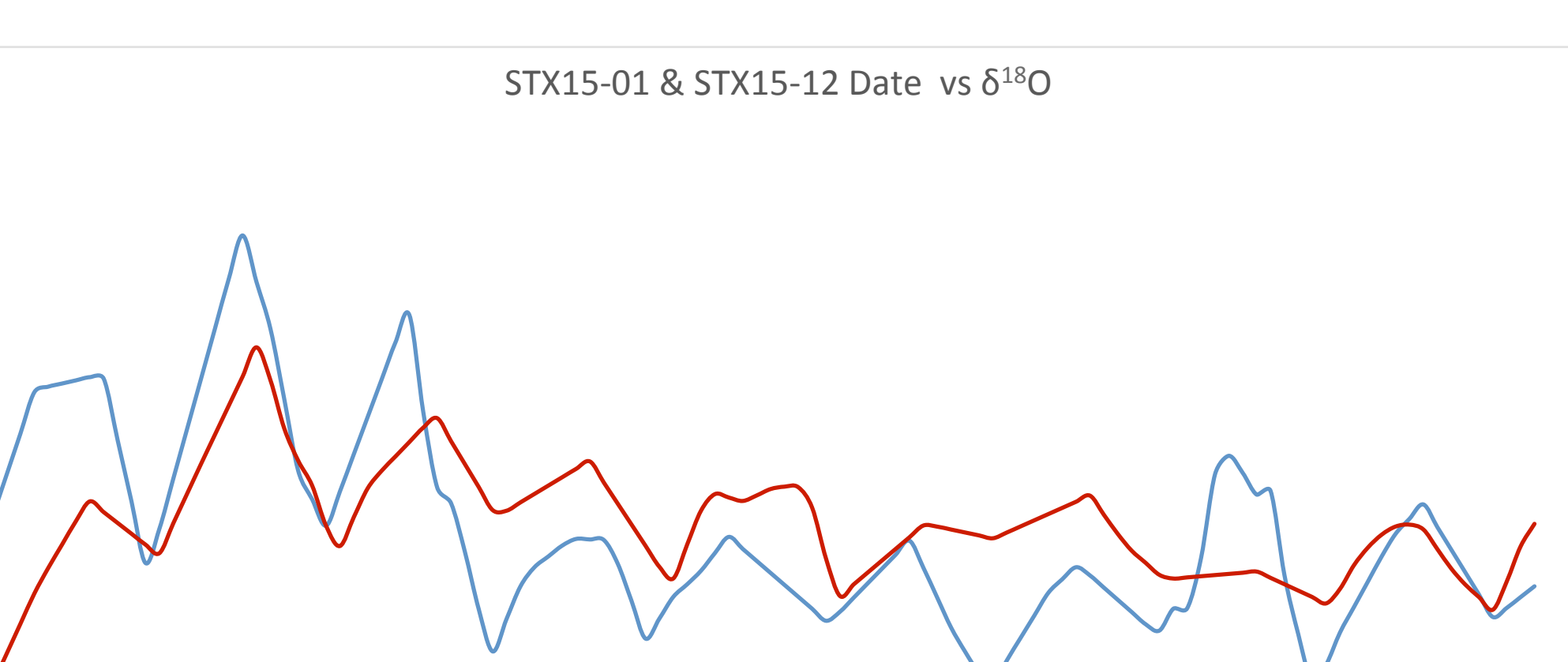

Figure $5:$ Comparison of Stable oxygen isotope $\left(\delta^{1 / 0}\right)$ data from STX15-01 and
STX15-12 coral cores.

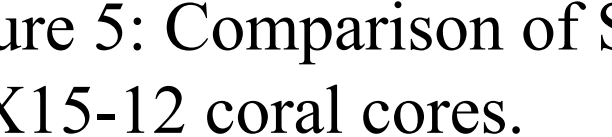

Modern

TTX15-01

35.0.

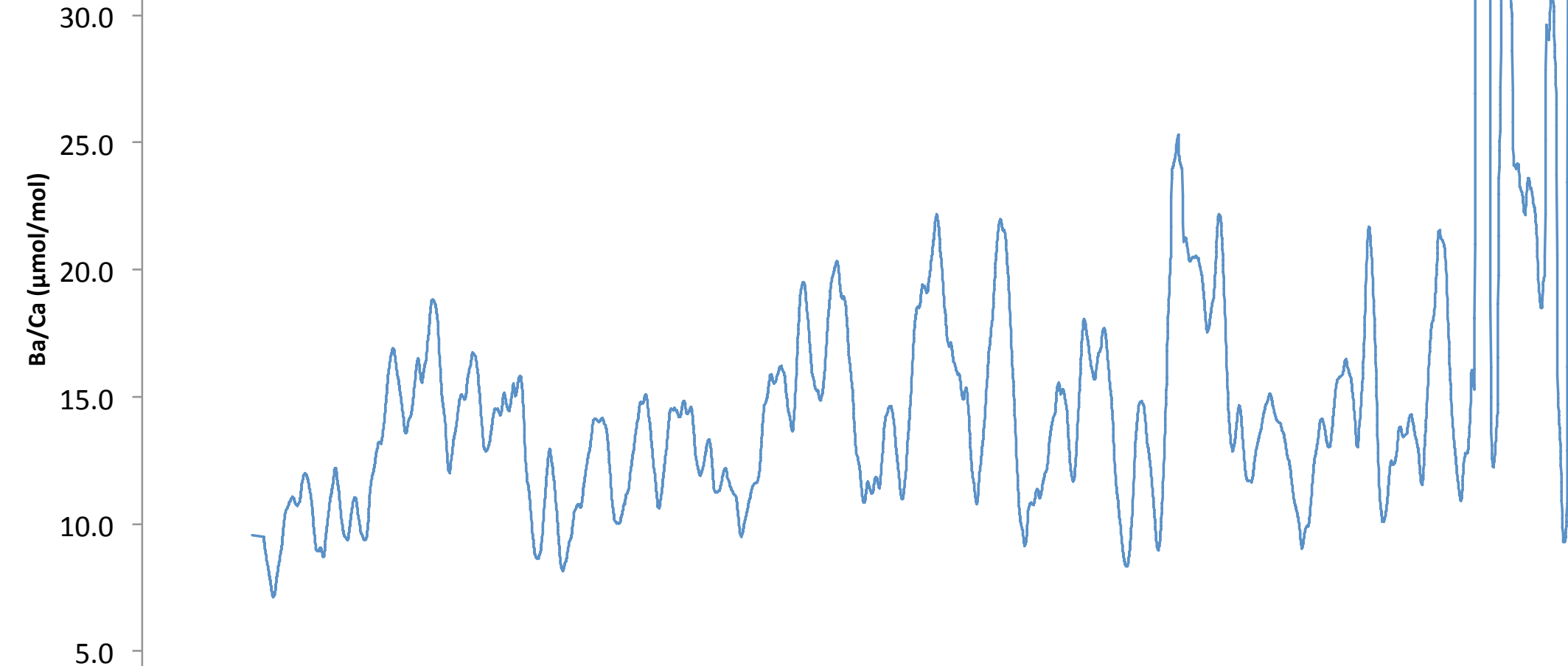

Tigure 7: Barium to calcium ratio
2005 to 2015 C.E (Lane, 2016).

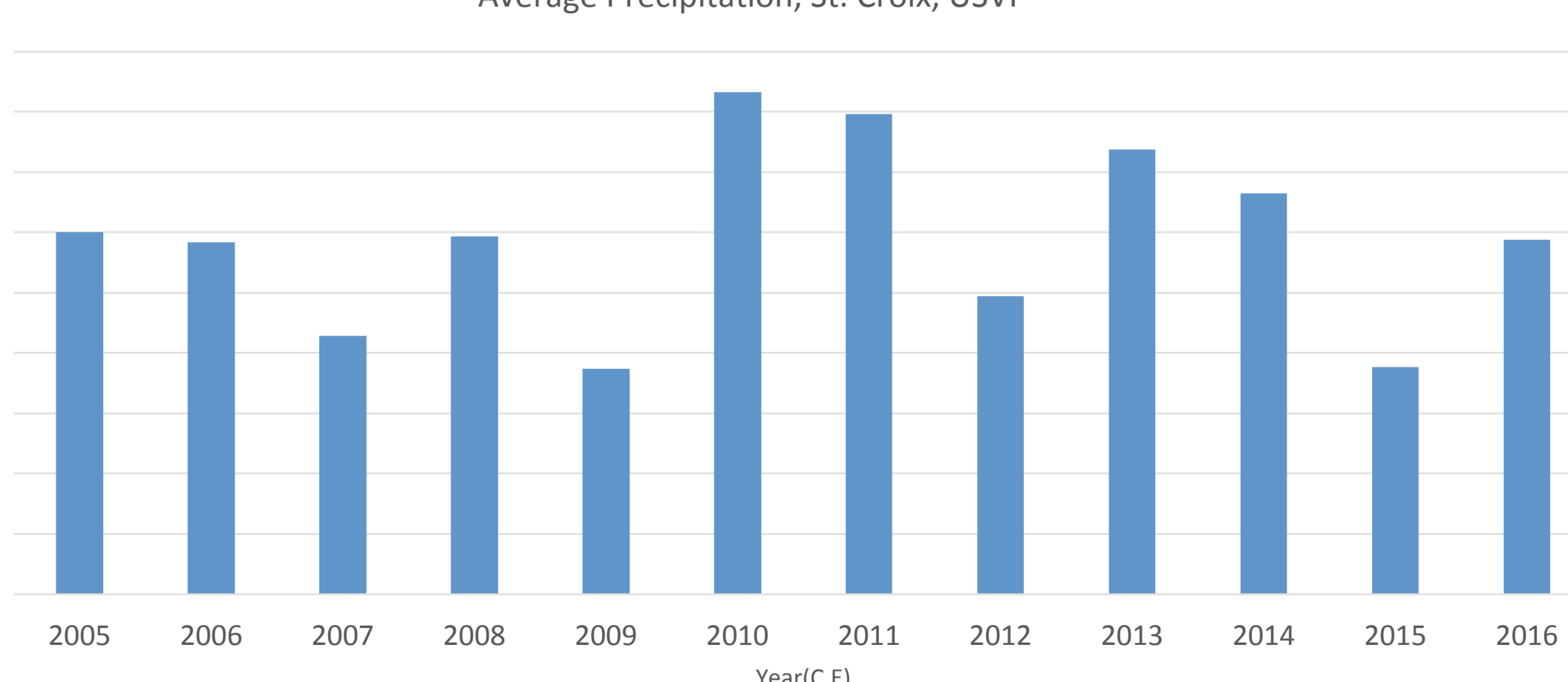

Table 1 :
Croix.
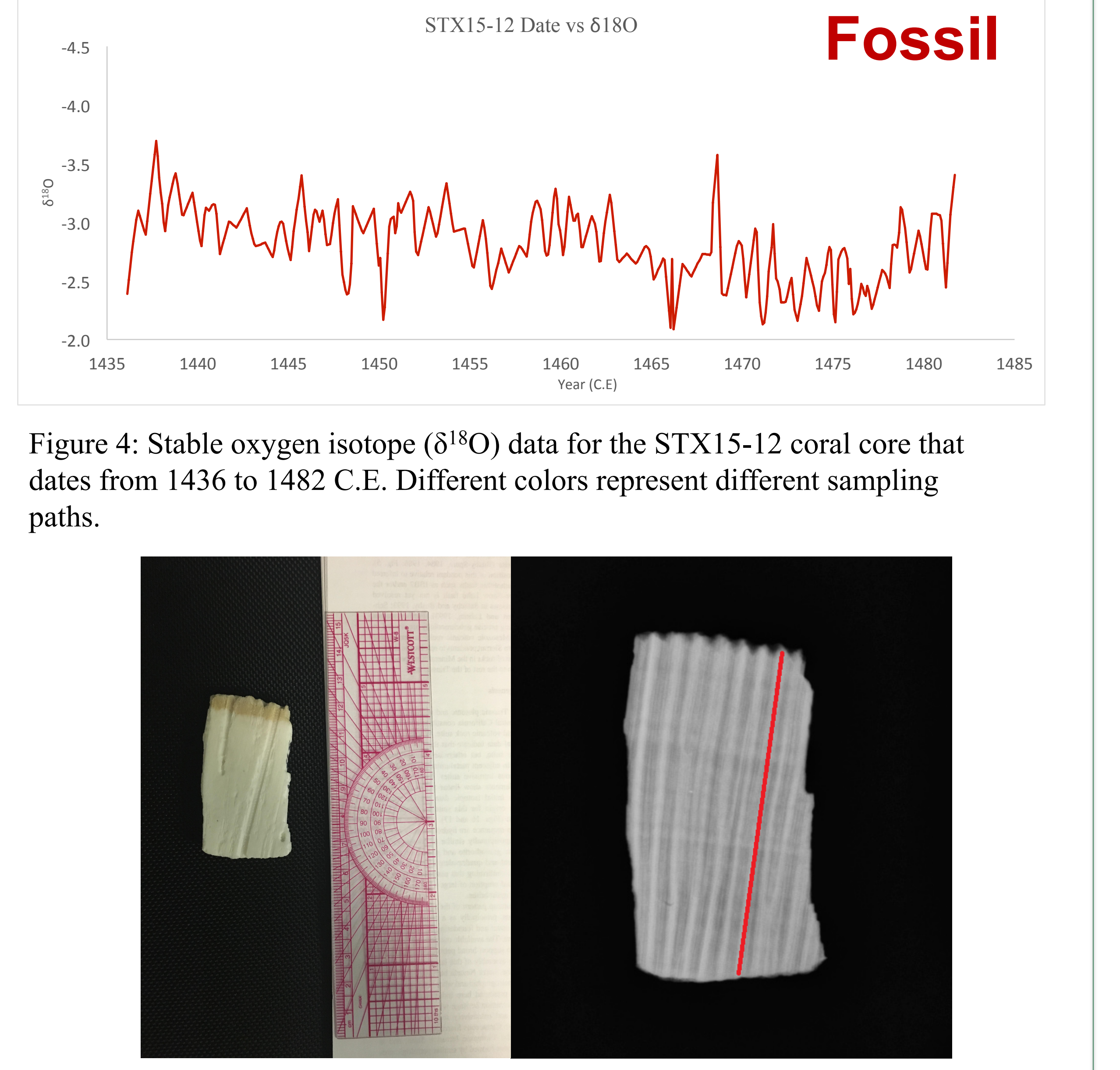

Kigure 6: On the left is the coral STX15-01 affer being milled for Gasbench
RMSS On the right is the approximate LA-ICP-MS path of STX15-01 overlain

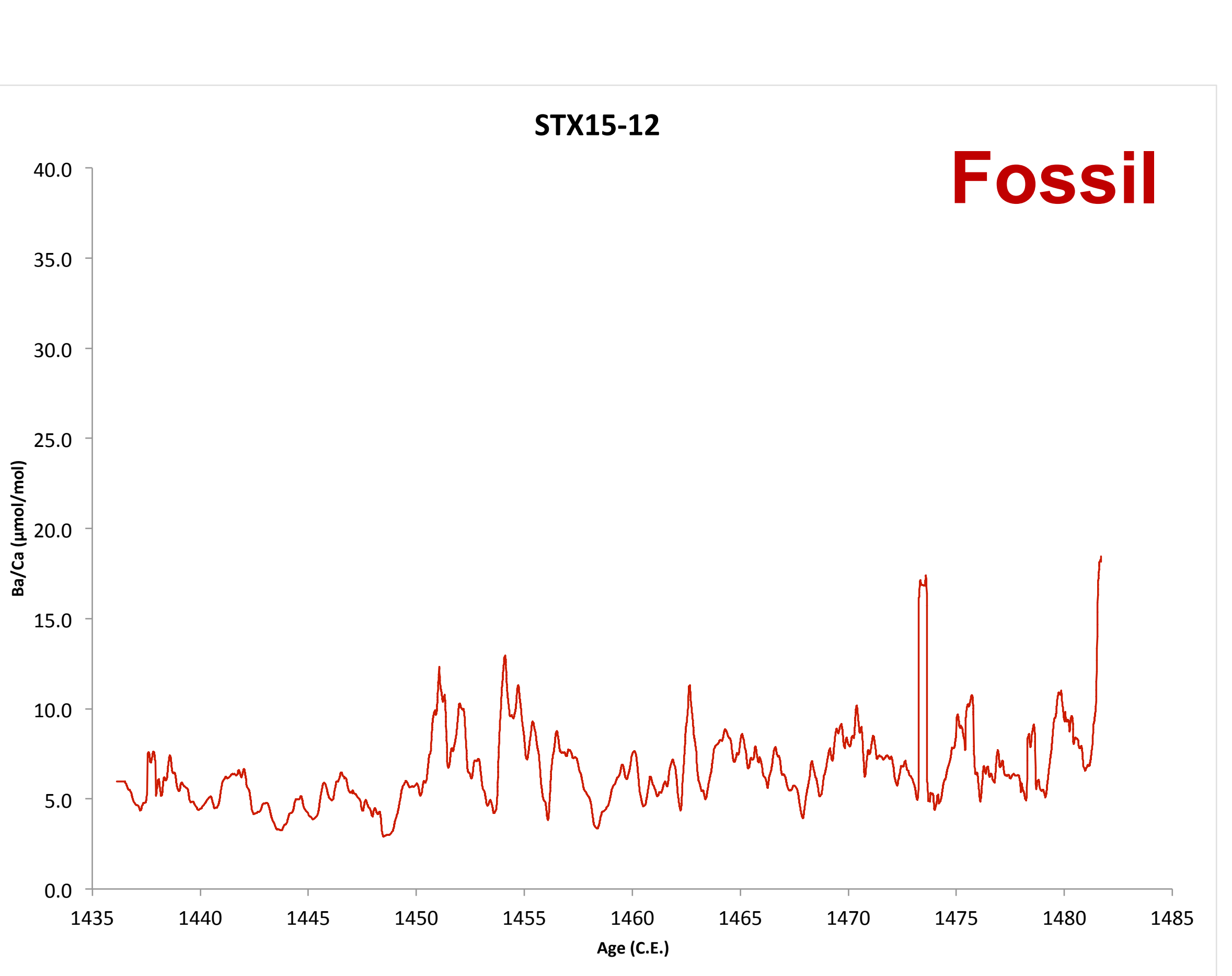

Figure 8 : Barium to calcium ratios
1436 to 1482 C.E (Lane, 2016).

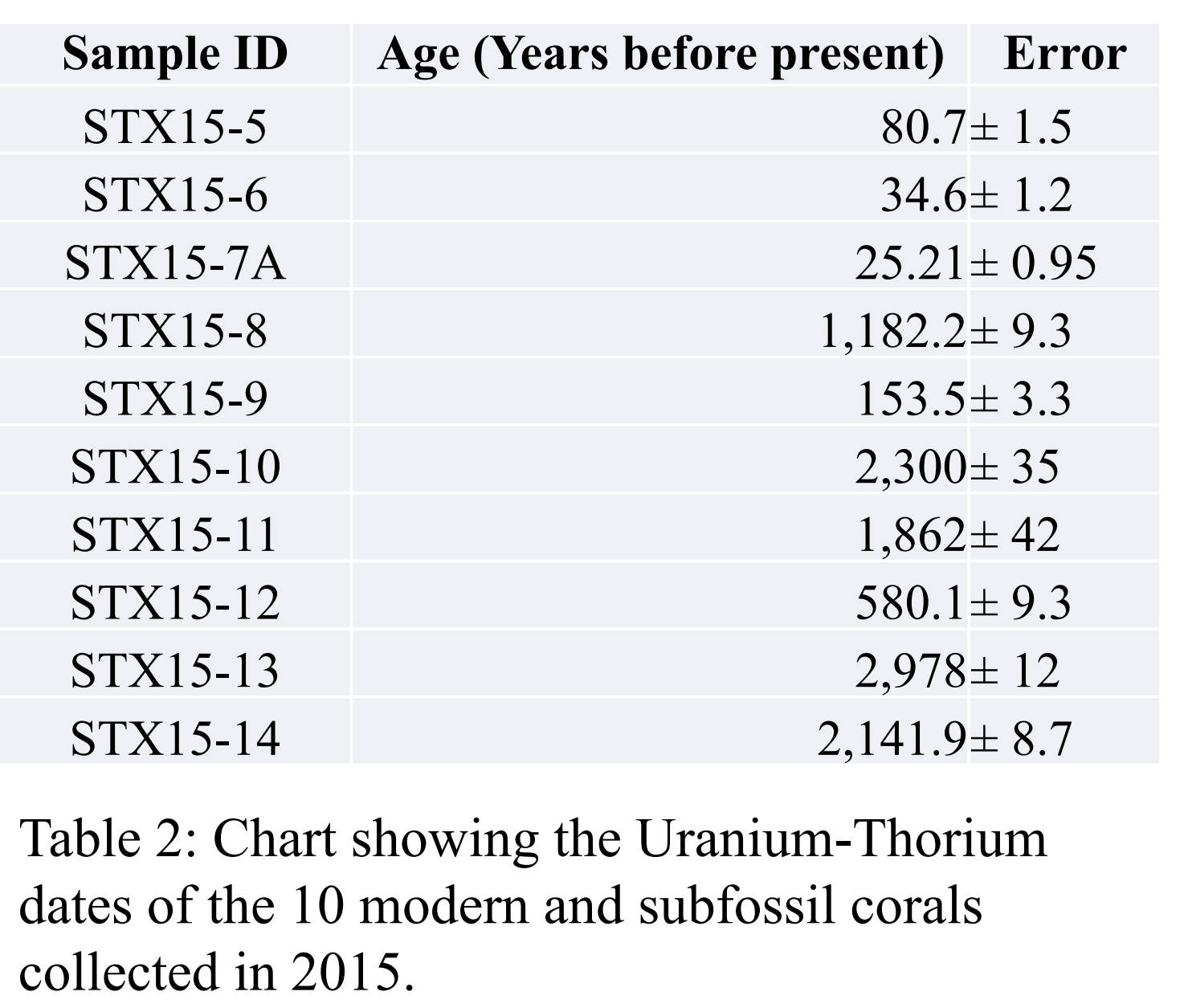

Discussion

Stable Isotope Data

作 - in bohithe modern and subfossil coral cores (Figures 3,4 , and 5 ). - STXI5-01 and STXIS-12 are similarly depleted in o ${ }^{\circ} \mathrm{O}$. Every $0.2 \%$ 政 SST (Guzman, Tudhope; 1998).

SST (Gizhe The remain static since the $15^{\text {th }}$ century or some other forcing is at work. Ba/Ca Data

Significant barium replacement of calcium during the precipitation of agonite from seawater indicates an increase in the an) ( Saha, et al; 2016). (

\section{Conclusions}

- Various forcings in opposite directions (SST and SSS) are likely responsible for the depletion of $\delta^{18} \mathrm{O}$ values in coral skeletal material. SST is an unlikely culprit.

Increased $\mathrm{Ba} / \mathrm{Ca}$ values indicate that modern sediment flux exceeds that of $15^{\text {th }}$ century runoff.

- Increased human activity on the island over the last several centuries has likely contributed to an increase in sediment flux to the local reefs.

- Further analysis of the other corals collected in 2015 and several other corals collected in 2016 would provide the resolution necessary to establish a comprehensive record of climate variability in St. Croix.

\section{Future Work}

- Additional corals were collected during the May 2016 field season. These cores have yet to be analyzed

Additional isotope and trace element geochemistry will be performed on additional STX15 coral samples.

\section{Acknowledgements}

We thank Dr. Douglas Gamble, Dr. Scott Nooner, Konrad Grochocki, Sarah Kwon, and

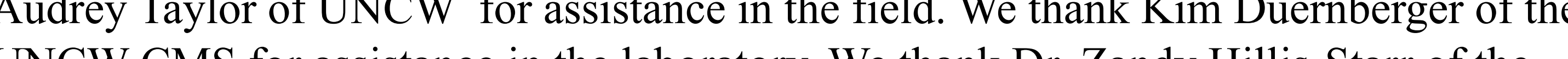
UNCW CMS for assitance in he laboratory. We thank Di. Zandy Hillis-Start of the of California, Davis for access to the Stable Isotope Laboratory. We thank Dr. River Shen of National Taiwan University for radiometric dating. We thank Steve Rounds for making thin sections.

References

Guzmán HM, Tudhope AW (1998) Seasonal variation in skeletal extension rate and stable Caribbean reef coral Siderastrea siderea. Marine Ecology Progress Series, 166, 109-118. Lane, CS (2017) Water Chemistry, Phytoplankton, and Sediment Dynamics of Nearshore Habitats in Salt River Bay, St. Croix, USVI. Final Grant Report, Department of Interior
McCulloch, M., Fallon, S., Wyndham, T., Hendy, E., Lough, J., \& Barnes, D. (2003). Coral record of increased sediment flux to the inner Great Barrier Reef since European Settlement. Nature, 421 (6924), 727-730. doi:10.1038/nature0136 Saha, N., Webb, G. E., \& Zhao, J. X. (2016). Coral skeletal geoc
water quality Science of the Total Environment, $566,652-684$. 